\title{
OS LIMITES NORMATIVOS DA MOBILIDADE HUMANA EM PROCESSOS DE INTEGRAÇÃO REGIONAL: OS EFEITOS DA PANDEMIA DE COVID-19 E AS RESTRIÇÕES À CIRCULAÇÃO DE PESSOAS NA UNIÃO EUROPEIA E NO MERCOSUL
}

\author{
THE NORMATIVE LIMITS OF HUMAN MOBILITY IN REGIONAL \\ INTEGRATION PROCESSES: THE EFFECTS OF THE COVID-19 \\ PANDEMIC AND RESTRICTIONS ON THE MOVEMENT OF PERSONS IN \\ THE EUROPEAN UNION AND MERCOSUR
}

\author{
João Mauricio Malta Cavalcante Filho \\ Universidade Federal de Pernambuco - UFPE - (Recife, PE, Brasil) \\ Eugênia Cristina Nilsen Ribeiro Barza \\ Universidade Federal de Pernambuco - UFPE - (Recife, PE, Brasil)
}

Recebimento: 29 maio 2020

Aceitação: 12 ago. 2020

\begin{abstract}
Como citar este artigo / How to cite this article (informe a data atual de acesso / inform the current date of access):
CAVALCANTE FILHO, João Mauricio Malta; BARZA, Eugênia Cristina Nilsen Ribeiro. Os limites normativos da mobilidade humana em processos de integração regional: os efeitos da pandemia de COVID-19 e as restrições à circulação de pessoas na União Europeia e no MERCOSUL. Revista da Faculdade de Direito UFPR, Curitiba, v. 65, n. 2, p. 177205, maio/ago. 2020. ISSN 2236-7284. Disponível em: https://revistas.ufpr.br/direito/article/view/74155. Acesso em: 31 ago. 2020. DOI: http://dx.doi.org/10.5380/rfdufpr.v65i2.74155.
\end{abstract}

\section{RESUMO}

Os blocos regionais que optaram pelo mercado comum condicionam uma ordem normativa de disciplinamento da mobilidade humana, a qual encontrou limites nacionais acentuados pela crise de saúde relacionada à pandemia de COVID-19. No cenário de restrições à mobilidade por ocasião do novo coronavírus, este artigo trata das barreiras jurídicas à liberdade de circulação de pessoas em espaços integrados; em especial, no âmbito da União Europeia e do MERCOSUL. Contrapondo as experiências à luz do direito comunitário e do direito da integração regional, objetiva-se analisar o disciplinamento da mobilidade em arranjos integrativos, discutindo os desafios e os limites da livre circulação de pessoas nos modelos europeu e mercosulino. Para tanto, propõe-se reflexão a partir da teoria da integração econômica, no contexto de globalização confrontada por limites nacionais de saúde e ordem pública. Metodologicamente, utiliza-se da revisão bibliográfica e do método hipotético-dedutivo, para testar a hipótese de que a mobilidade é disciplinada em sistemas regionais, conferindo abertura às competências estatais em situações de crise. Os resultados indicam que as ordens regionais analisadas admitem limites à mobilidade humana. A pandemia, com ápice registrado no primeiro semestre de 2020, ilustra essa dinâmica de regulamentação da livre circulação de pessoas, revelando que os sistemas regionais toleram restrições nacionais no espaço comum, confirmando a hipótese aventada. Na União Europeia, as restrições à circulação desafiam a estrutura comunitária, enquanto no MERCOSUL reafirmam o modelo fortemente intergovernamental do bloco. Constatase que as medidas impactam o espaço integrado, devendo observar os limites das ordens regionais e das recomendações internacionais. 


\title{
PALAVRAS-CHAVE
}

Integração regional. Livre circulação de pessoas. União Europeia. MERCOSUL. COVID-19.

\begin{abstract}
ABTRACT
The regional blocs that have opted for the common market create a normative order for disciplining human mobility, which found national limits accentuated by the health crisis related to the pandemic of COVID-19. In the context of restrictions on mobility due to the new coronavirus, this article deals with legal barriers to the free movement of persons in integrated spaces, especially within the European Union and the Mercosur. Contrasting the experiences in the light of Community law and the law of regional integration, the objective is to analyze the disciplining of mobility in integrative arrangements, discussing the challenges and limits to the free movement in the European and Mercosurian models. For this, a reflection is proposed based on the theory of economic integration, in the context of globalization confronted by national limits on health and public order. Methodologically, a bibliographic review and the hypothetico-deductive method is used, testing the hypothesis that mobility is disciplined in regional systems, giving openness to state competences in crisis situations. The results indicate that the analyzed regional systems admit limits to human mobility. The pandemic, which peaked in the first half of 2020, illustrates this dynamic of the free movement of persons, revealing that regional systems tolerate national restrictions in the common space, confirming the suggested hypothesis. In the European Union, restrictions on circulation challenge the community structure; in Mercosur, they reaffirm the bloc's strongly intergovernmental model, appearing that the measures impact the integrated space while observing the limits of regional orders and international recommendations.
\end{abstract}

\section{KEYWORDS}

Regional integration. Free movement of persons. European Union. Mercosur. COVID-19.

\section{INTRODUÇÃO}

Os processos de integração regional, intensificados no contexto de globalização econômica, condicionam o surgimento de ordens normativas destinadas a disciplinar as relações jurídicas desenvolvidas no espaço integrado. Os arranjos integrativos alteram as relações tradicionais desenvolvidas entre Estados, territórios e fronteiras, criando um sistema regional de disciplinamento da mobilidade humana, sobretudo naquelas experiências em que se optou pelo mercado comum, que tem como uma de suas principais características a livre circulação de pessoas, consolidada na União Europeia (UE) e ainda em evolução no âmbito do Mercado Comum do Sul (MERCOSUL).

Essa liberdade de circulação não é, todavia, incondicionada. Ao contrário, encontra limites no direito comunitário e no direito da integração regional. Tais limites são reforçados em situações de crise, em face de ameaças à ordem pública, à segurança interna e, sobretudo, à saúde pública, como ocorre na pandemia causada pelo novo coronavírus, tecnicamente identificado como coronavírus da síndrome respiratória aguda grave 2 (SARS-CoV-2), causador da coronavirus disease 2019 (COVID19). Nesses casos, as exceções à mobilidade são toleradas pelos blocos, reafirmando competências 
nacionais de controle. As restrições configuram respostas visíveis dos governos nacionais e das instituições regionais aos desafios impostos pela pandemia, com ápice registrado no primeiro semestre de 2020, pressionando os direitos de mobilidade, tanto na UE, quanto no MERCOSUL.

Diante do contexto apresentado, que tensiona a globalização econômica e confronta os auspícios de livre circulação propostos pelo regionalismo, o presente artigo trata do tema do disciplinamento da mobilidade humana em espaços integrados, discutindo seus limites normativos nos arranjos regionais. Para tanto, foca nas restrições à circulação de pessoas, adotadas por ocasião da pandemia de COVID-19, no âmbito europeu e mercosulino, cujos processos foram selecionados por apresentarem normativas que regulamentam o tema, permitindo um paralelo de análise entre ambos.

A partir de uma reflexão acerca dos processos de integração, centrada no dado da mobilidade humana, aplica-se a teoria jurídica da integração regional para reinterpretar os efeitos jurídicos da pandemia em causa. Ao tratar da problemática dos limites normativos da livre circulação de pessoas em blocos regionais, o artigo objetiva analisar a regulamentação da mobilidade em arranjos integrativos. Especificamente, objetiva-se discutir os desafios e os limites da liberdade de circulação de pessoas no âmbito europeu e mercosulino, utilizando o contexto da pandemia em referência.

Para atingir os objetivos, utiliza-se de uma abordagem metodológica qualitativa, valendo-se de revisão bibliográfica, sob marco da teoria econômica da integração, e da análise de fontes do direito europeu e mercosulino. Para estruturar a investigação, aplica-se o método hipotético-dedutivo, levantando-se a hipótese de que a mobilidade humana é disciplinada em sistemas regionais de modo a conferir margem para atuação estatal em situações de crise. Parte-se da premissa de que os sistemas regionais, sejam comunitários, sejam intergovernamentais, admitem restrições à circulação de pessoas, reforçando competências de controle, de modo que a pandemia citada ilustra a dinâmica de regulamentação da mobilidade nesses processos. Isto é, os blocos regionais toleram a atuação estatal em contextos de crise, reiterando a premissa de que a área de livre circulação é possível desde que os membros conservem competências de ação.

Em face do panorama apresentado, o artigo trata, na primeira seção, dos fundamentos da integração regional e da mobilidade humana no contexto de inflexão da globalização em face da pandemia. Na segunda seção, discute-se o disciplinamento normativo da circulação de pessoas na UE e no MERCOSUL. Na terceira seção, apresentam-se as medidas restritivas efetivamente adotadas nos blocos, destacando-se seus impactos. Ao final, conclui-se que as restrições nacionais à circulação afetam a integração, devendo-se observar os sistemas regionais e as recomendações internacionais. 


\section{INTEGRAÇÃO REGIONAL E MOBILIDADE HUMANA EM UM CONTEXTO DE PANDEMIA E DE INFLEXÃO DA GLOBALIZAÇÃO}

A integração regional é concebida enquanto um processo de associação interestatal, firmado sob bases jurídicas específicas, que conformam um arranjo regional destinado à consecução de objetivos comuns (DIZ; JAEGER JÚNIOR, 2015, p. 140). Os arranjos integrativos demandam esforços significativos de interação por parte dos Estados que deles participam, na medida em que levam à formação de um sistema normativo próprio, que interage com a ordem jurídica interna e internacional, objetivando regulamentar as relações jurídicas desenvolvidas no espaço integrado.

Após sucessivas ondas de regionalismo (MESQUITA, 2019, p. 7), sobretudo no cenário pósSegunda Guerra, os blocos regionais proliferaram em um contexto de internacionalização da economia, marcando a difusão de experiências integracionistas. A partir de novos contornos dados às competências soberanas clássicas, com uma pluralidade de instâncias que transcendem o monopólio normativo estatal, as nações foram levadas a desenvolverem novas formas de interação, revelando-se a integração regional como alternativa para os desafios até então apresentados. Em um cenário de interdependência e de incremento dos fluxos transfronteiriços de bens, serviços, capitais e pessoas, acelerados pela globalização econômica, os arranjos regionais emergiram como centros disciplinadores das expectativas globais em espaços de integração.

Considerando a dimensão econômica que esteve na base do processo, a teoria clássica da integração propõe a interpretação do fenômeno como um projeto orientado por etapas sucessivas que buscam reduzir ou eliminar as discriminações entre as economias nacionais dos países participantes (BALASSA, 1961, p. 13). A partir da concessão de privilégios aduaneiros, conduz-se a um estado de fato, isto é, um efetivo espaço integrado, que intensifica a circulação dos fatores de produção. Sob esse aporte, como salienta Feferbaum (2017, p. 158), a integração regional está associada à integração de mercados nacionais em um mercado mais amplo, parcial ou total, com a progressiva eliminação de barreiras jurídicas à circulação dos fluxos transfronteiriços.

Apesar da relevância do aspecto econômico, à medida que o projeto regional avança, o ordenamento jurídico resultante da integração passa a irradiar efeitos para além dos aspectos comerciais. Fatores relacionados às dimensões sociais e políticas passam a conformar a estrutura dos blocos, que exigem a adoção de normativas para facilitar a integração em domínios classicamente disciplinados na esfera nacional, a exemplo da mobilidade humana, no intuito de formar um sistema normativo capaz de equilibrar as competências dos Estados-membros e das instâncias regionais.

Sobretudo a partir da fase do mercado comum, caracterizada pela livre circulação de bens, serviços, capitais e pessoas no espaço comum, as transformações jurídicas promovidas pelos blocos 
econômicos tendem a alterar as relações entre Estados, fronteiras e mobilidade humana. Isso porque os blocos passam a conformar espaços comuns de mobilidade, os quais proporcionam privilégios de circulação aos cidadãos, redefinido as territorialidades tradicionais (GÜLZAU; MAU; ZAUN, 2016, p. 166).

As normativas regionais que vigoram nesses espaços comuns afetam, particularmente, a circulação de pessoas, assumindo esquemas que abarcam desde a simples remoção dos requisitos de visto para viagens intrarregionais, até um tratamento mais abrangente, que concede o direito de residir e trabalhar em outro Estado-membro, afetando a condição jurídica dos cidadãos regionais. Em contrapartida, no que tange aos fluxos externos, os arranjos integrativos trazem desafios para disciplinar, de forma harmônica, os direitos de mobilidade dos nacionais de países terceiros, mas sem retirar completamente as competências nacionais de controle.

A partir de então, forma-se um complexo normativo destinado a regulamentar a mobilidade humana nos espaços comuns, condicionando uma governança regional dos deslocamentos, tanto intrarregionais, representado pela livre circulação de pessoas, quanto inter-regionais, em relação às migrações externas. As normas, regras, princípios e procedimentos de tomada de decisão passam a demandar a redefinição da agenda dos blocos, a convergência de posição e a adaptação de legislações, políticas e práticas de migração e mobilidade. Em consequência, a mobilidade humana, utilizada em sentido lato como o deslocamento humano na perspectiva internacional, a fim de englobar a perspectiva de livre circulação, bem como a ideia de migração (VILLAMAR; ALMEIDA, 2017, p. 8), assume papel central nas experiências regionais, desafiando o disciplinamento do fluxo de pessoas cuja intensidade é marcante na globalização.

Enquanto termo global, a mobilidade configura uma metáfora conceitual, que captura a impressão de que o mundo está em fluxo contínuo, com pessoas, culturas, objetos, capitais, negócios, serviços, doenças, mídia, imagens, informações e ideias circulando pelo planeta (SALAZAR, 2019, p. 18). Em um contexto de globalização, que abarca uma rede de intensificação das interconexões em escala mundial (GIDDENS, 2006, p. 23), os fluxos transfronteiriços de bens, serviços, informações, capitais e pessoas são impactados. Tem-se um processo dinâmico que pressiona e influencia tanto as políticas nacionais, quanto as relações multilaterais e regionais, gerando complexas interações entre o nível normativo nacional, regional e global em termos de mobilidade.

Por um lado, ordens nacionais evocam a defesa da soberania e o controle do fluxo de estrangeiros como competências internas. Por outro lado, reconhecem a necessidade de cooperar com outros atores, mormente no âmbito regional, que traz um quadro normativo visando à regulamentação dos direitos de circulação e residência nos espaços integrados. Como resultado dessa dialética, os 
blocos econômicos têm o desafio de transportar o disciplinamento da mobilidade humana, de uma prerrogativa unicamente nacional, para a esfera de discussão regional, em virtude dos compromissos assumidos.

Em consequência, os processos de integração formam centros normativos destinados a disciplinar a circulação de pessoas nos espaços integrados resultantes dos sistemas regionais criados pelo direito comunitário e pelo direito da integração regional. Em ambos os casos, os arranjos regionais apontam possibilidades jurídicas que visam encontrar soluções normativas mutuamente acordadas para enfrentamento de problemas comuns em matéria de mobilidade, com grau de vinculação que varia a depender do modelo. Buscando avançar na livre circulação de pessoas e harmonizar o tratamento das migrações, formam-se ordens regionais que vigoram ao lado do direito interno e do direito internacional, atuando em um sistema multinível de disciplinamento.

A ascensão de uma sociedade globalizada, interdependente economicamente e composta por novas formas de organização internacional, arranjos regionais e instituições com amplitude global (LECHNER; BOLI, 2019, p. 2) impacta as formas de gerenciamento da mobilidade humana e como os Estados lidam com este fenômeno. Se, por um lado, há uma pressão pela liberalização seletiva de fatores de produção, pressionando os ordenamentos jurídicos nacionais a reduzirem barreiras às esferas de mobilidade no âmbito regional e, paulatinamente, no âmbito global, por outro lado, esses mesmos sistemas, no contexto de globalização, são tentados a selecionarem fluxos de pessoas, reintroduzindo controles por questões de segurança, saúde e ordem pública.

Por essa razão, a mobilidade humana, em um cenário de globalização e regionalismo, também revela os contextos de desigualdades no mundo atual (HEES; VENY; HEES, 2018, p. 44). A circulação internacional de pessoas é desenvolvida de forma assimétrica no mundo globalizado (VENTURA, 2015, p. 57). Isso significa que, embora a globalização tenha contribuído para o estudo da mobilidade, o paradigma da imobilidade continua relevante, mormente em relação às estruturas sociais e normativas que facilitam certos movimentos e impedem outros (SALAZAR, 2019, p. 18), evidenciando os que estão excluídos das facilidades de deslocamento por questões de ordem pública, segurança, ou mesmo restrições de saúde pública em contextos de crise.

A dinâmica dual da mobilidade humana, facilitada para alguns e enrijecida para outros, repercute, também, no âmbito regional, com limites relacionados à regularidade dos fluxos, às necessidades internas e às demandas de normalidade. Por conseguinte, os blocos são desafiados por tratamentos que põem em xeque a utopia de um mundo de livre mobilidade, colocando em risco a era de ouro da livre circulação em espaços regionais. Isso porque a tendência de regionalismo, acelerada no final do século XX com a onda de globalização contemporânea, é desafiada por tendências de 
reavivamento de nacionalismos, aliadas à fragmentação de blocos (COSTA; VIEIRA, 2019, p. 146), levando ao retorno do tratamento nacional de questões de circulação de pessoas.

Em última instância, tem-se desconfiado do próprio cenário de globalização que marcou a ascensão dos projetos integracionistas e os esquemas regionais de livre mobilidade. A integração tem sido pressionada por reações que suspeitam do processo de globalização, com ascensão de um populismo antiglobalização com efeitos de desintegração já sentidos no bloco europeu. No conjunto, as correntes populistas nacionais se opõem à globalização liberal, à imigração em massa e à política de consenso dos últimos tempos, prometendo dar voz àqueles que se sentem negligenciados pela elite cada vez mais distante. Trata-se de uma reação a elites políticas, bem como à destruição, real ou percebida, de identidades, e aos efeitos negativos da globalização, consubstanciados em crises cíclicas (FLEW, 2019, p. 17), empurrando a globalização e o regionalismo para um momento de inflexão.

Os efeitos são sentidos nos processos de integração, a partir das tentativas de retomada do nacionalismo metodológico e da crença de que o Estado-nação seria o ente mais adequado, isto é, a principal instância, senão a única possível, para disciplinar os desafios da contemporaneidade diante de situações de crise, sejam elas de segurança ou de saúde pública, com tentativas de reafirmar competências soberanas. As repercussões jurídicas são significativas e envolvem a criação de novos muros, físicos e jurídicos, para as esferas de mobilidade, sobretudo a mobilidade humana, com o acirramento de controles de fronteiras internas e externas dos blocos regionais, passando pela desconfiança de projetos integracionistas e de suas funções regulamentadoras.

Não bastassem esses efeitos, a sociedade global é desafiada a lidar com uma pandemia que acentua a inflexão da globalização e repercute sobremaneira nas liberdades regionais: o vírus SARSCoV-2, causador da COVID-19 e que alegadamente teve sua origem em Wuhan, província de Hubei, na parte central da China, espalhou-se rapidamente desde fins de 2019, levando a Organização Mundial da Saúde (OMS) a declarar uma pandemia em 2020 (MUCELIN; D’AQUINO, 2020, p. 18), com impactos jurídicos significativos nos espaços regionais, na medida em que as respostas incrementam o isolamento social e restringem a circulação de pessoas no âmbito interno, regional e internacional. Neste novo cenário global, que escancara os efeitos de uma globalização que pode fazer circular bens, informações e pessoas, mas também doenças, em uma velocidade significativa, os projetos regionais, em especial, a UE e o MERCOSUL, são particularmente afetados ao lidarem com os efeitos da pandemia.

Isso porque, os blocos regionais, a partir da fase do mercado comum, buscam reunir esforços para garantir o direito à livre circulação como princípio central da integração. No entanto, manter os benefícios econômicos desses movimentos transfronteiriços e limitar a propagação da COVID-19 
colocou desafios normativos aos ordenamentos comunitários e regionais, na medida em que se intensificaram os limites nacionais à mobilidade, levando à adoção de medidas restritivas para proteger a saúde das pessoas. Em consequência, apostou-se na limitação da mobilidade humana, tolerando-se as restrições impostas pelos Estados-membros em relação aos cidadãos do bloco e aos nacionais de países terceiros, tanto na UE, quanto no MERCOSUL, em uma retomada do protagonismo dos entes estatais.

Nesse sentido, da mesma forma que a integração regional implicou uma reconfiguração jurídica dos elementos tradicionais do Estado, a pandemia de COVID-19 também reconfigurou as categorias jurídico-políticas tradicionais (WERMUTH; MORAIS, 2020). A crise global de saúde alterou as estruturas de liberdade e segurança dos Estados, transformando os efeitos da globalização econômica, diante do fechamento de fábricas, retração do comércio, alteração de preços de commodities e limitação de transportes internos e internacionais de cargas e passageiros. Em suma, redefiniu-se uma ordem mundial que cede diante de restrições às interações transfronteiriças.

O contexto apresentado revela que as esferas de mobilidade não circulam de forma incondicionada, nem mesmo nos espaços regionais de integração. Ao contrário, encontram limites no direito interno, e também no direito regional, mormente em situações de crise, especialmente marcadas por ameaças à ordem pública, que se caracteriza pela sua fluidez e mutabilidade, embora seja reflexo de toda legislação, representando a moral básica de uma nação e protegendo as necessidades do Estado (DOLINGER; TIBURCIO, 2018, p. 445). No caso da pandemia em análise, as restrições à mobilidade materializam preocupações de disseminação de contágio e de sobrecarga dos sistemas de saúde, gerando uma introversão normativa, no sentido de reafirmar competências nacionais para gerenciar a crise nos espaços integrados.

Desse modo, a integração regional funciona como uma metáfora da dinâmica da mobilidade humana no contexto de inflexão da globalização em tempos de pandemia: libera-se o movimento, mas para algumas pessoas e em determinadas condições, de acordo com os compromissos normativos regionais assumidos, podendo o Estado retomar as competências de controle diante de situações préestabelecidas, como a ameaça à saúde pública em causa. Flexibilizam-se parcialmente os limites territoriais, em prol da redefinição de novos espaços e territorialidades, mas sem deixar de conferir margem de atuação aos Estados-membros, que reforçam tais limites em contextos de crises capazes de repercutir nos regimes jurídicos de livre circulação existentes. 


\section{O DISCIPLINAMENTO NORMATIVO DA MOBILIDADE HUMANA EM PROCESSOS DE INTEGRAÇÃO: EFEITOS E LIMITES DA LIVRE CIRCULAÇÃO DE PESSOAS NA UNIÃO EUROPEIA E NO MERCOSUL}

A mobilidade humana opera em uma dinâmica peculiar no bojo de processos de integração, em face de sistemas normativos destinados a regulamentar a circulação de pessoas nos espaços comuns. Graças aos efeitos jurídicos desses sistemas regionais, observa-se uma cisão normativa no conceito de mobilidade humana até então discutido.

No âmbito regional, a ideia geral de mobilidade humana opera efeitos específicos sob a forma de gestão migratória e sob a forma de livre circulação de pessoas, esta última o foco deste artigo. Diferentemente da noção tradicional de migração, que aduz o acirramento de fronteiras, relacionando-se ao poder de um Estado de controlar o ingresso e permanência de estrangeiros no seu território (MOURA, 2015, p. 632), a livre circulação implica abertura de fronteiras, com possibilidade de cidadãos transitarem sem barreiras no âmbito regional, como corolário social da integração. Nesse sentido, é entendida como a prerrogativa de movimentar-se, para exercer atividades econômicas ou não, bem como disponibilizar-se no espaço regional sem que sejam impostas restrições injustificadas. A presente seção, ao focar na dimensão da mobilidade atrelada à circulação de pessoas, discute a regulamentação da liberdade associada a essa circulação e os limites normativos a ela impostos pelos modelos europeu e mercosulino, cujas restrições foram potencializadas no contexto de pandemia apresentado.

\subsection{O DISCIPLINAMENTO NORMATIVO DA LIVRE CIRCULAÇÃO DE PESSOAS NA UNIÃO EUROPEIA À LUZ DO DIREITO COMUNITÁRIO}

A UE é resultado de um longo processo de integração, sujeito a avanços e retrocessos, mas que conseguiu atingir nível significativo de integração ao garantir a liberdade de circulação de pessoas como uma pedra angular do arranjo europeu. Com origens no cenário pós-Segunda Guerra, a partir do incentivo à cooperação econômica e do esforço conjunto em prol de um projeto político de paz e de reestruturação (DEL’OLMO; ROTTA, 2016, p. 104), a integração europeia consolidou um contexto que permite a adoção de normas comunitárias em temas relativos à mobilidade humana.

O alto grau de institucionalização alcançado decorre, em larga medida, da estrutura normativa do bloco. Graças à adoção do modelo supranacional, regido pelo direito comunitário ou europeu, admite-se a aplicação de mecanismos decisórios e legislativos comuns que garantem a formulação de normativas europeias nas matérias de interesse regional, como a livre circulação de pessoas, permitindo a atuação das instâncias supranacionais na condução do bloco. A consolidação 
do direito comunitário, por meio de princípios relativos à aplicabilidade imediata, efeito direto e primazia do ordenamento comunitário (DIZ; JAEGER JÚNIOR, 2015, p. 153), conduz a um sistema normativo que leva à criação de um amplo espaço de livre circulação. A estrutura comunitária implica um sistema normativo aplicado à mobilidade humana, com vistas a assegurar a livre circulação de pessoas nesse espaço comum, enquanto se tenta harmonizar uma política migratória europeia, sendo o direito europeu a forma jurídica que busca garantir o equilíbrio do bloco, diante da pluralidade de Estados-membros.

Por essa razão, a UE tem sido frequentemente considerada o caso paradigmático em matéria de mobilidade regional. Por meio dos princípios do direito comunitário, os indivíduos podem invocar prerrogativas concedidas pelo direito da UE perante os tribunais nacionais, bem como a prevalência do quadro jurídico europeu diante de disposição interna inconsistente. Ademais, as instâncias supranacionais, a exemplo da Comissão Europeia e do Tribunal de Justiça da UE, garantem a supervisão comunitária do bloco, tutelando o acesso aos direitos de livre circulação (ACOSTA, 2017, p. 159).

No que tange à evolução normativa da liberdade de circulação de pessoas, cumpre esclarecer que essa liberdade já estava disciplinada no início do processo integrativo, associada a necessidades marcadamente econômicas, na medida em que objetivava instrumentalizar o fluxo de trabalhadores, a prestação de serviços e o livre trânsito de mercadorias. Em termos de mobilidade, a prerrogativa estava relacionada à circulação de trabalhadores, posteriormente estendida à livre circulação de pessoas, independentemente de condição econômica ativa, até se assentar na cidadania da UE.

No âmbito do direito europeu originário, o início do processo de integração contemplou o Tratado de Paris de 1951, o qual criou a Comunidade Europeia do Carvão e do Aço (CECA), seguido pela assinatura do Tratado de Roma, de 1957, com o objetivo de constituir a Comunidade Econômica Europeia (CEE), e do tratado constitutivo da Comunidade Europeia de Energia Atômica (Euratom). As disposições sobre a livre circulação estavam previstas desde o Tratado de 1957, contemplando a livre circulação de trabalhadores e a liberdade de estabelecimento (COSTA; VIEIRA, 2019).

Com a assinatura do Ato Único Europeu, firmado em 1986, em paralelo às discussões do acordo de Schengen, buscou-se avançar na consolidação do mercado comum (EUR-LEX, 1987). Mediante a criação de um espaço sem fronteiras internas, no qual a livre circulação fosse assegurada, seria possível consolidar um mercado único. A partir de então, passa-se de um modelo da integração econômica negativa, pautada pela mera liberalização, para a integração positiva (HERZ; HOFFMAN, 2004, p. 12), com formulação de políticas comuns sobre os vários aspectos da integração. 
Seguindo a mudança de orientação normativa, a evolução do bloco europeu deslocou a livre circulação de pessoas de uma perspectiva unicamente econômica e laboral para uma liberdade extensível a todos os cidadãos europeus, a partir da noção de cidadania da UE delineada pelo Tratado de Maastricht, de 1992. Esse tratado introduziu a noção de cidadania da UE, da qual qualquer nacional de um Estado-membro se beneficia automaticamente, alterando o tratamento tradicional acerca da livre circulação, ao associar a liberdade de circulação de pessoas à liberdade de circulação e residência de cidadãos europeus no espaço comum (PARLAMENTO EUROPEU, 2020). Portanto, a liberdade está dissociada da perspectiva laboral, sendo precisamente na cidadania comunitária que se assenta o direito de livre circulação e residência na UE.

No direito comunitário originário, o Tratado de Lisboa, de 2009, confirmou este direito de livre circulação e residência, que está também incluído nas disposições gerais relativas ao Espaço de Liberdade, Segurança e Justiça, no intuito de criar um espaço sem fronteiras internas, com livre circulação de pessoas e com medidas integradas de gestão da fronteira externa e de imigração (PARLAMENTO EUROPEU, 2020). Portanto, a liberdade de circulação, a um só tempo, encontra amparo no direito comunitário e representa o pilar de sustentação, não só do mercado interno, mas, também, da cidadania comunitária.

Em termos de instrumentalização jurídica da livre circulação de pessoas, porém, a principal conquista da integração europeia reside na consolidação do espaço Schengen. O acervo Schengen se refere a regras que foram originalmente adotadas fora da UE, no âmbito da cooperação intergovernamental, tendo como objetivo a abolição dos controles nas fronteiras comuns, a partir do acordo de Schengen de 1985 e de sua convenção de aplicação de 1990 (BRUYCKER, 2018, p. 301). O acervo foi incorporado ao quadro legislativo comunitário, cuja área de livre mobilidade não se confunde com o espaço comum criado pela UE, sendo o espaço Schengen composto por 26 países, que incluem 22 Estados-membros da EU - Alemanha, Áustria, Bélgica, Dinamarca, Eslováquia, Eslovênia, Espanha, Estônia, Finlândia, França, Grécia, Holanda, Hungria, Itália, Letônia, Lituânia, Luxemburgo, Malta, Polônia, Portugal, República Tcheca e Suécia -, acrescido de Estados associados, como Noruega, Islândia, Suíça e Listenstaine.

Dentre as realizações de Schengen, destacam-se a abolição dos controles nas fronteiras internas para todas as pessoas, a harmonização e o reforço dos controles nas fronteiras externas, uma política comum em matéria de vistos, incentivo à cooperação policial e judiciária e adoção de sistema integrado de informação, com controles previstos no Código de Fronteiras Schengen, sob sigla CFS (EUR-LEX, 2016). 
Não obstante a evolução normativa apresentada, o acervo Schengen forma um regime, fronteiriço e de mobilidade, dual. Isto é, um espaço que desmobiliza fronteiras internas, favorecendo os direitos de mobilidade das pessoas autorizadas a circular, enquanto, externamente, reforçam-se os controles, endurecendo limites exteriores. Essa dinâmica é tensionada por vetores que resultam na reintrodução de fronteiras internas, diante de pressões relacionadas à chegada maciça de nacionais de países terceiros, ou mesmo em situações de crise, como a pandemia de COVID-19, que pressionou a reintrodução de limites e de barreiras à mobilidade.

O regime dual é expresso, ainda, nos direitos de mobilidade atrelados à condição jurídica da pessoa que está circulando. Em relação aos seus beneficiários, a principal prerrogativa representa a possibilidade de entrar no espaço Schengen mediante apresentação de bilhete de identidade ou passaporte válido, podendo circular livremente, reforçando a ideia de construção de um espaço comum onde os cidadãos europeus não são típicos estrangeiros. Por outro lado, para nacionais de países terceiros, demandam-se requisitos que podem abarcar desde a exigência de visto para determinadas nacionalidades, formando-se uma fortaleza burocrática (VIEIRA; COSTA, 2018, p. 5), até a submissão a controles pormenorizados nas fronteiras externas.

Cumpre destacar, ainda, que os direitos de mobilidade no âmbito da UE são complementados pelo direito comunitário derivado, sobretudo por meio da Diretiva 2004/38/CE (EUR-LEX, 2004), relativa ao direito de livre circulação e residência dos cidadãos da UE e dos membros das suas famílias. A diretiva destina-se a incentivar o exercício do direito à livre circulação e residência nos Estados-membros, reduzindo formalidades administrativas e delimitando as restrições à entrada e à residência. Isso significa que a liberdade de circulação de pessoas, no bojo da integração europeia, admite amplos direitos de entrada e pós-entrada relacionados com a residência.

Não obstante, essa liberdade não é absoluta. Pelo contrário. O direito europeu admite restrições por parte dos Estados-membros, mormente em contextos de ameaça à ordem pública, segurança interna e saúde pública. As limitações jurídicas são expressas no âmbito das normativas analisadas, em especial, no CFS e na Diretiva 2004/38, que incluem salvaguardas que protegem os interesses dos Estados-membros de ônus excessivo para o sistema de assistência social, permitindo que estes restrinjam a liberdade de circulação por razões de ordem pública, segurança interna e saúde pública.

No âmbito do espaço Schengen, o CFS prevê a possibilidade de reintrodução temporária de controles nas fronteiras internas, mormente nos arts. 25 a 35 (EUR-LEX, 2016). Especificamente, em caso de uma ameaça grave à ordem pública ou à segurança interna em um Estado-membro,que exija ação imediata, autoriza-se a reintrodução, a título excepcional e de forma imediata, do controle nas 
fronteiras internas por período limitado, além de admitir a restrição de entrada em caso de ameaça de saúde pública. Da mesma forma, a Diretiva 38/2004 (EUR-LEX, 2004) autoriza o afastamento por razões de ordem pública, segurança pública ou saúde pública, a exemplo do art. 29, que admite medidas restritivas da livre circulação por parte do Estado-membro de acolhimento em face de doenças com potencial epidêmico definidas pelos instrumentos da OMS.

Em face das limitações, situações como a pandemia de COVID-19 levam à materialização das medidas restritivas, com imposição, por parte dos Estados-membros, de limites à forma como o direito de circular é exercido na UE, revelando uma tentativa de reafirmação normativa dos Estados. As respostas à crise do novo coronavírus exemplificaram como o sistema regional se reabre à atuação do Estado-membro na tentativa de contenção de ameaças ao espaço comum. Entre as medidas, que serão tratadas com mais detalhe na última seção, os países de Schengen, nas fases iniciais de combate, focaram na reintrodução de controles em suas fronteiras internas, com proibições generalizadas de viagens, exigências de autoisolamento e autorização de entrada apenas para determinados estrangeiros. Como explicam Carrera e Luk (2020, p. 37), o SARS-CoV-2 desafiou as bases de Schengen, a livre circulação e a cidadania da UE, uma vez que as respostas foram conduzidas por políticas unilaterais e nacionalistas.

Portanto, a partir da análise do modelo europeu, é possível perceber que, não obstante o quadro comunitário em matéria de livre circulação, as competências dos Estados-membros continuam relevantes, sobretudo em face de restrições por ordem pública, segurança interna e saúde pública. Em contextos de crise, como aquele causado pelo novo coronavírus, mesmo os regimes jurídicos de livre circulação já consolidados sofrem restrições, demonstrando que a liberdade em tela não é incondicionada.

\subsection{O DISCIPLINAMENTO NORMATIVO DA CIRCULAÇÃO DE PESSOAS NO MERCOSUL À LUZ DO DIREITO DA INTEGRAÇÃO REGIONAL}

No que tange ao MERCOSUL, apesar de o bloco não ter alcançado um mercado comum, já que não considera a completa abolição de fronteiras internas, nem a ampla consolidação de um espaço de livre circulação de pessoas nos moldes da UE, é possível constatar esforço regional no sentido de disciplinar a mobilidade, como ora se discute.

Em termos institucionais, o MERCOSUL é considerado uma organização regional, que atua sob a forma de bloco econômico, criado pelo Tratado de Assunção, em 1991, assinado por Argentina, Brasil, Paraguai e Uruguai. O bloco tenta instituir um mercado comum, mediante a liberalização de 
fatores de produção, originando-se dos esforços associativistas e da aproximação estratégica entre Brasil e Argentina, que culminou em relações interestatais mais estreitas para solucionar problemáticas comuns. A partir da convergência e da cooperação, o arranjo sul-americano buscou o desenvolvimento conjunto, o fortalecimento das economias nacionais e uma melhor inserção na globalização econômica, muito embora o processo tenha evoluído para além da esfera comercial, avançando nos aspectos jurídicos da circulação de pessoas.

Diferentemente da UE, o bloco mercosulino aposta na intergovernabilidade, que se refere a arranjos por meio dos quais os Estados, em condições e situações específicas, que podem ser controladas e operacionalizadas por meio dos seus governos, cooperam entre si em assuntos de interesse comum. Em consequência, o MERCOSUL passa a operar conforme o direito da integração regional, que faz emergir uma ordem normativa própria, distinta daquela que rege o direito comunitário, mas também distinta do direito interno e do direito internacional clássico (BOHLKE, 2002). O direito da integração regional se revela fruto de entendimentos recíprocos entre os Estados, apostando na harmonização legislativa nas áreas pertinentes ao projeto regional, em detrimento de normativas comunitárias diretamente aplicáveis. Em outras palavras, demanda-se um esforço contínuo de adaptação normativa nacional ao sistema criado pelo bloco e um esforço de incorporação normativa nos ordenamentos nacionais, em face dos limites da ordem interna de cada partícipe (DIZ; JAEGER JÚNIOR, 2015, p. 149).

A partir da intergovernabilidade prevalecente, coloca-se o ritmo da integração a cargo de cada Estado Parte, já que se trata de países que ainda relutam em conferir aspectos relevantes da soberania nacional para instituições regionais. Os Estados Partes se agarram ao dogma da soberania (VENERAL; KNIHS, 2018, p. 271), preferindo acordos de cooperação, por vezes demandando procedimentos de internalização, em detrimento de estratégias mais incisivas, como a adoção de políticas comuns e a institucionalização da plena liberdade de circulação de pessoas.

Em matéria de mobilidade humana, a própria estrutura normativa do MERCOSUL já confere abertura significativa à atuação aos Estados Partes, em termos de incorporação e aplicação das normativas regionais. Isso significa que o direito mercosulino não abarca transferências relevantes de competências estatais, em matéria de livre circulação de pessoas, para instâncias regionais, estando na dependência da atuação dos Estados Partes, em face da estrutura intergovernamental prevalecente. No entanto, mesmo sem a supranacionalidade normativa dos moldes europeus, não se pode olvidar que o arranjo sul-americano conseguiu conformar uma ordem jurídica regional que apresentou evolução considerável em termos de mobilidade humana. 
Em linhas gerais, a evolução normativa da mobilidade segue a evolução geral do bloco. Na fase de transição do MERCOSUL, de 1991 a 1994, não se discutia expressamente a livre circulação de pessoas no Tratado de Assunção, que trazia apenas uma menção genérica à livre circulação de fatores produtivos. Em outras palavras, a circulação de pessoas era tratada de forma instrumental aos objetivos econômicos do mercado comum, como forma de incrementar trocas comerciais e o turismo na região. Como explica Mendes (2016, p. 145), faltava um plano de ordenamento regional para a mobilidade humana, haja vista que as propostas de facilitar o trânsito internacional de cidadãos dos Estados Partes partiam da perspectiva de integrar mercados, considerando apenas subsidiariamente o fator de mobilidade. Em consequência, as normativas do período resumiam-se à inserção de canais privilegiados em portos e aeroportos, para trânsito de nacionais e residentes do bloco, e a questões técnicas relacionadas à harmonização de procedimentos administrativos para o controle integrado de fronteiras.

Na fase de institucionalização, a partir de 1994 e até o início dos anos 2000, o MERCOSUL passou a regulamentar a mobilidade humana no espaço regional a partir da harmonização dos documentos de viagem válidos para a circulação no bloco, bem como pela adoção de normas destinadas a facilitar a integração e circulação nas áreas fronteiriças. A partir desse período, observase o incremento da dimensão social da integração, com iniciativas voltadas ao reconhecimento de direitos aos trabalhadores migrantes e aos direitos à seguridade social, a exemplo da Declaração Sociolaboral e do Acordo Multilateral da Seguridade Social (SALZMANN, 2012, p. 172).

O período de guinada na regulação do tema, porém, ocorre a partir do início dos anos 2000, com a proliferação qualitativa e quantitativa de acordos relativos à migração e às problemáticas associadas à mobilidade humana. Devido ao relançamento do MERCOSUL, no início dos anos 2000, após crise econômica e política, repensou-se o regionalismo, pondo em questão as orientações prevalecentes e abrindo caminho para incorporação de novos itens à agenda regional, incluindo a livre circulação, associada a uma questão sociopolítica, e não puramente econômica (BRUMAT; ACOSTA, 2019, p. 58). O sujeito em mobilidade passa, então, a ocupar o centro do projeto regional.

Em termos de livre circulação de pessoas, destaca-se a harmonização dos documentos de viagem válidos para o trânsito no espaço regional, garantindo passagem facilitada nas fronteiras internas, dispensando-se passaporte. Em termos de gestão migratória, destaca-se a adoção da Declaração de Princípios Migratórios de Santiago, em 2004, que ajudou na harmonização normativa em matéria de mobilidade humana, inclusive em relação aos nacionais de países terceiros, ao propor convergência para as políticas migratórias dos países, a busca pela regularidade migratória e a reafirmação da soberania no controle de fronteiras (VIEIRA; COSTA, 2018, p. 14). 
Nesse período, observa-se um salto qualitativo no disciplinamento da circulação de pessoas na região, a partir dos marcos regulatórios referentes aos Acordos sobre Migração e Residência de 2002 (MERCOSUL, 2002). O acervo de residência e migração no MERCOSUL é composto por acordos referentes à Regularização das Migrações Internas dos Cidadãos do MERCOSUL e por acordos sobre Residência para os Nacionais dos Estados Partes do MERCOSUL, com vigência a partir de 2009 (MOURA, 2015, p. 633). Dentre as principais inovações normativas, mencionam-se: a facilitação da regularização da situação migratória na região para os nacionais dos países mercosulinos, a garantia da igualdade de direitos e a possibilidade de os nacionais dos Estados do MERCOSUL requererem a residência em outro Estado Parte com base na nacionalidade, estabelecendo uma área de livre residência na região.

Os acordos apontam o desejo de avançar em uma política de livre circulação de pessoas, ao regular o processo de obtenção de residência permanente e temporária, bem como ao buscar solução para a situação de cidadãos dos Estados Partes, a partir da concessão de residência para aqueles que já se encontram no país receptor. Apesar dos esforços, na prática, os acordos instituíram uma livre circulação apenas em base bilateral, isto é, entre o país de nacionalidade do beneficiário e o país de residência, não se adotando livre circulação ampla (SALZMANN, 2012, p. 165).

Finalmente, a partir de 2010, com o Plano de Ação para a Cidadania Mercosulina, (MERCOSUL, 2010), reconheceu-se a necessidade de uma política de livre circulação de pessoas, a fim de que os nacionais dos países do bloco não sejam mais tratados unicamente como estrangeiros regionais, mas, sim, como cidadãos mercosulinos. Em consequência, devem gozar de um estatuto jurídico favorecido em matéria de circulação, a partir de um programa de ação que assente a livre circulação em uma base jurídica de cidadania regional. Dentre as ações, realçam-se: a facilitação do trânsito e da passagem fronteiriça no espaço integrado, a simplificação de trâmites burocráticos, a desburocratização de procedimentos de controle, a harmonização dos documentos migratórios e a ampliação das áreas de controle integrado de fronteiras.

Não obstante se aponte certa estagnação recente em matéria de mobilidade, diante de percepções mais conservadoras e nacionalistas da integração, voltadas para a dimensão econômica (BRUMAT; ACOSTA, 2019), é possível observar que houve um esforço normativo no sentido de se disciplinar a circulação de pessoas. Mesmo que não se adote um amplo direito de livre circulação nos termos europeus, a evolução do bloco revela a formação de um direito da integração regional que regulamenta o tema, inicialmente voltado a questões laborais, passando pela harmonização de documentos de viagens e pela facilitação de deslocamentos transfronteiriços, até chegar a uma concepção de livre circulação associada ao estatuto jurídico da cidadania regional. 
Porém, assim como o direito comunitário, também o direito mercosulino coloca limites à mobilidade no espaço regional, conferindo aos Estados possibilidade de ação em situação de ameaça à ordem pública, à segurança e, principalmente, à saúde pública. Dentre os limites impostos nas normativas analisadas, mencionam-se os Acordos de residência, normativa que expressamente reconhece que as pessoas que tenham obtido sua residência têm direito a entrar, sair, circular e permanecer livremente no território do país de recepção, sem prejuízo de restrições excepcionais impostas por razões de ordem pública e de segurança pública (MERCOSUL, 2002). Da mesma forma, o art. $4^{\circ}$ dessa normativa reconhece que a legislação interna do Estado Parte de ingresso pode exigir certificado médico expedido por autoridade médica migratória ou outra autoridade sanitária oficial, no qual conste a aptidão psicofísica do requerente da residência temporária, em conformidade com as normas internas do país de recepção.

A estrutura intergovernamental do bloco confere abertura significativa de atuação aos Estados, diante da ausência de supranacionalidade e de supervisão comunitária, estando o processo na dependência da disponibilidade de cada país para avançar nas liberdades regionais. A abertura do sistema mercosulino aos Estados Partes culmina em maior flexibilidade de atuação diante das situações de crise, tornando o ente estatal o protagonista na contenção da mobilidade, cujos limites foram revelados por ocasião da pandemia de COVID-19. A pandemia ilustrou a dinâmica de funcionamento do direito mercosulino, ao conferir amplos poderes aos Estados, com aplicação de limitações em matéria de circulação de pessoas. Incentivados por um sistema normativo que se abre consideravelmente aos Estados Partes, os países da região adotaram medidas unilaterais, valendo-se das prerrogativas nacionais que culminaram em restrições à mobilidade no espaço regional, decretando-se quarentena obrigatória, toque de recolher, suspensão geral de voos, fechamento de fronteiras e restrições à imigração (RIGGIROZZI, 2020, p. 8), como será tratado na seção seguinte.

Como resultado, tem-se uma sobreposição do interesse nacional em relação ao regional, já que as respostas se afastaram da concepção de livre circulação e se assentaram em uma espécie de soberania sanitária, com interesses nacionais fortalecidos. Em síntese, o papel do Estado tende a substituir o interesse regional na aplicação de limites à mobilidade, pelo retorno às fronteiras nacionais fechadas. Nesse sentido, a pandemia enfrentada é sintomática para ilustrar os limites normativos da circulação, graças às restrições adotadas nos blocos referidos, como se passa a analisar. 


\section{RESTRIÇÕES À MOBILIDADE HUMANA EM ESPAÇOS REGIONAIS: AS LIÇÕES DA PANDEMIA DO NOVO CORONAVÍRUS E OS IMPACTOS JURÍDICOS PARA A LIVRE CIRCULAÇÃO DE PESSOAS}

A liberdade de circulação de pessoas, apesar de ser reconhecida como um valor do mercado comum e da cidadania regional nos blocos analisados, não é ilimitada. Os arranjos integrativos admitem restrições à mobilidade humana, por razões de ordem pública, segurança interna e saúde pública. Sobretudo em contextos de crise, fatores associados a instabilidades políticas, pressão nas fronteiras regionais, ameaça terrorista, ou mesmo ameaças à saúde pública, acirram as competências nacionais de controle, expondo a dinâmica de disciplinamento da livre circulação no espaço integrado.

As respostas à pandemia de coronavírus, em especial, revelaram-se como exemplos paradigmáticos que ilustram o disciplinamento da mobilidade no âmbito regional. Isso porque a construção de um espaço de livre circulação de pessoas tem se mostrado possível se, e na medida em que, os Estados-membros conservem possibilidades de atuação em situações específicas, que, no caso analisado, são materializadas na crise de saúde pública. As restrições concretas adotadas pelo modelo europeu e mercosulino, discutidas nesta seção, expõem as dificuldades normativas de manter ou alcançar um espaço de livre circulação de pessoas no cenário de expansão da COVID-19, revelando as contradições e os desafios jurídicos enfrentados pelos blocos em termos de mobilidade humana, tendo-se observado pressão significativa pela retomada do protagonismo estatal nos esforços de contenção da pandemia.

Diante de um problema específico de ordem pública, manifestada na ameaça à saúde pública e respaldada na soberania sanitária, o ente estatal retoma a dianteira das medidas de contenção. A atuação dos arranjos regionais, enquanto um dos valores da integração regional, é desafiada pelos impactos dessas medidas restritivas na liberdade de circulação de pessoas, daí surgindo a necessidade de se equilibrar as limitações e os impactos da restrição na livre circulação de pessoas.

No caso da COVID-19, o surto se espalhou rapidamente desde sua suposta origem em Wuhan, na China (KRAEMER et al., 2020). Em 31 de dezembro de 2019, a OMS recebeu informações acerca de casos de pneumonia de causa até então desconhecida provenientes de Wuhan. Em janeiro de 2020, já era possível identificar o vírus responsável pelas infecções, o SARS-Cov-2, variante de coronavírus que causa a COVID-19 (MUCELIN; D’AQUINO, 2020). Apesar de o surto da doença ter sido relatado em dezembro de 2019, a OMS declarou emergência de saúde pública de interesse internacional em 30 de janeiro de 2020, e pandemia, que acontece quando os novos 
patógenos transcendem fronteiras, contaminando pessoas em outros países e continentes, em 11 de março de 2020 (OLIVEIRA NETO; GARCIA; SPINUSSI, 2020, p. 2).

Em resposta, foram observadas medidas de contenção, como a redução, e até a suspensão, de viagens, aliadas a um panorama de isolamento social (BITTENCOURT, 2020, p. 170) que repercutiu na suspensão de reuniões de massa, fechamento de empresas e de espaços públicos não essenciais e distanciamento físico. As medidas reverberaram, ainda, na circulação internacional de pessoas, com fronteiras restringidas, e até fechadas, inclusive em espaços regionais de livre mobilidade.

A adoção dessas medidas restritivas, por sua vez, impacta os direitos de mobilidade no interior dos blocos analisados. Quando as ações implicam o fechamento de fronteiras, consequentemente se observa uma redução na dinâmica da circulação de pessoas, afetando a vida daqueles que trabalham, estudam, compram, buscam tratamento médico, viajam ou simplesmente se deslocam, no espaço integrado, ao amparo do direito regional. Sob o aporte normativo, o direito comunitário e o direito da integração precisam abarcar as possibilidades de atuação estatal diante da situação de crise, sob pena de violação do sistema regional. Paralelamente, as iniciativas nacionais de contenção da mobilidade ilustram o disciplinamento da livre circulação de pessoas no bojo de processos de integração, que comportam limites normativos, sob pena de a própria liberdade de circulação atuar como fator de desagregação do bloco.

Além do âmbito regional, a forte atuação interna é contraposta por esquemas de coordenação e colaboração internacionais, em uma espécie de governança e garantia global da saúde (WERMUTH; MORAIS, 2020, p. 15), que vêm à tona em cenários de pandemia, atuando em múltiplos níveis. Como exemplo, tem-se a OMS, um anteparo mundial das problemáticas relativas à saúde, que contribui para uma governança global do tema e da questão sanitária como materialização da ordem pública internacional. Propõe-se regra de saúde pública mundial, mas que não abre mão da atuação estatal para sua concretização, a qual reinterpreta uma ordem pública associada à saúde pública para justificar limitações à circulação de pessoas. No limite, o ente estatal é o responsável pela aplicação efetiva das recomendações propostas, em especial, pelos limites impostos à circulação internacional de pessoas, mormente no contexto de avivamento de nacionalismos, não obstante os esforços regionais e internacionais.

Cumpre reforçar, ainda, que não se está discutindo a efetividade de tais restrições nacionais na contenção da pandemia em tela. A uma, porque os resultados das restrições da mobilidade humana na contenção da pandemia exigem pesquisas na área médica, notadamente aquelas que se debruçam sobre a dinâmica epidemiológica. A duas, porque pesquisas existentes revelam que as restrições de 
viagem, embora se mostrem efetivas nas fases iniciais, podem ser menos efetivas quando a pandemia se instaura (KRAEMER et al., 2020; ORGANIZAÇÃO MUNDIAL DA SAÚDE, 2020), principalmente se comparadas a outras medidas, como a detecção e isolamento precoces dos casos, mudanças comportamentais e conscientização da população (CHINAZZI et al., 2020, p. 4).

Em relação à UE, durante a crise de saúde pública, os Estados-membros adotaram padrões restritivos em matéria de mobilidade humana que afetaram reflexamente a liberdade de circulação de pessoas no bloco. Nas fases iniciais, as limitações se valeram da abertura do direito comunitário para reintroduzirem fronteiras internas no âmbito do espaço Schengen. Como observado, os Estadosmembros podem introduzir controles temporários nas fronteiras internas em caso de ameaça previsível, ameaça imediata ou situação de deficiências relacionadas às fronteiras externas, o que revela uma tolerância do sistema normativo europeu para a atuação dos Estados na gestão da mobilidade.

Em março de 2020, o surto de coronavírus levou muitos Estados-membros à reintrodução de controles nas fronteiras internas com base na ameaça imediata às políticas públicas (UNIÃO EUROPEIA, 2020). A reintrodução do controle nas fronteiras internas, no entanto, deve permanecer uma exceção e respeitar o princípio da proporcionalidade, solidariedade entre os membros e não discriminação, a fim de não colocar em xeque a liberdade de circulação de pessoas na UE. Diante da estrutura supranacional e das amarras do direito europeu, que demandam uma supervisão comunitária, os Estados-membros devem notificar as instâncias supranacionais e os demais Estados acerca das medidas, especificando as razões e a duração das restrições.

Ainda assim, a reintrodução do controle nas fronteiras permanece como uma prerrogativa dos Estados, sendo frequentemente utilizada em contextos de crise, como na crise migratória em 2015 e na pandemia de COVID-19, em que países como Polônia, Islândia, Alemanha, Portugal, República Tcheca, Bélgica, Noruega, Suíça, Hungria, Áustria, Espanha, Estônia, Lituânia e Eslováquia reintroduziram temporariamente os controles de fronteira no contexto que exige ação imediata, enquanto países como Finlândia, Suécia, Dinamarca e França reintroduziram temporariamente os controles em face de ameaças a eventos previsíveis, nos termos do art. 25 e seguintes do CFS (EURLEX, 2016). As justificativas englobaram desde o apoio a medidas destinadas a conter a propagação do vírus, até o combate à ameaça terrorista contínua, que poderia se concretizar ante a vulnerabilidade dos Estados na pandemia, resultando no controle acirrado sobre o fluxo de pessoas no espaço regional (UNIÃO EUROPEIA, 2020).

Paralelamente, os países do bloco impuseram restrições explícitas à mobilidade humana, restringindo a entrada e saída de pessoas de seu território, incluindo a mobilidade intra-UE e intra- 
Schengen. Essas ações são definidas como proibições de entrada ou saída, o que significa que principalmente os não nacionais que não atendiam às condições de isenção foram automaticamente e categoricamente impedidos de entrar nesses países, configurando-se como proibições de viagem (CARRERA; LUK, 2020).

Como esclarece Szymańska (2020, p. 2), a pandemia tornou-se um grande desafio para o espaço Schengen, em particular, e para o direito europeu, em geral. Diante de uma crise, os Estadosmembros exigem maior liberdade para decidir se restauram ou ampliam os controles nas fronteiras. A crise de saúde pública confirmou a tendência de que, para a manutenção de um espaço de livre circulação de pessoas, busca-se garantir margem de intervenção estatal, sobretudo diante das situações de ameaça, em que as restrições à mobilidade humana são toleradas no ordenamento comunitário, mesmo em um sistema regido pela supranacionalidade com forte supervisão comunitária, como é o caso da UE. Não bastassem os desafios relacionados aos fluxos extracomunitários, que levam a uma contenção dos direitos de circulação, tornando-os cada vez mais semelhantes à migração de países terceiros (BARBULESCU, 2017), com distinção de tratamento entre europeus e não europeus e a ascensão de discursos nacionalistas, a COVID-19 tensionou ainda mais o modelo europeu de livre circulação vigente.

Além das restrições normativas à circulação de pessoas adotadas pelos Estados-membros, seguindo a moldura proposta pelo direito comunitário, as próprias instâncias supranacionais adotaram critérios tendentes a disciplinar a mobilidade no bloco. As contramedidas da UE buscaram contrabalançar as ações dos Estados-membros. No entanto, as iniciativas comunitárias também implicaram restrições significativas sobre a livre circulação nas fases iniciais, mantendo o protagonismo dos Estados-membros.

Dentre as principais ações imediatas em matéria de mobilidade, destacam-se as "Diretrizes europeias para medidas de gestão de fronteiras para proteger a saúde e garantir a disponibilidade de bens e serviços essenciais” (COMISSÃO EUROPEIA, 2020a), autorizando o Estado-membro a realizar verificações sistemáticas de todas as pessoas para entrar no espaço Schengen, a recusar a entrada de nacionais de países terceiros e a reintroduzir controles nas fronteiras internas, e a “Restrição temporária de viagens não essenciais à UE” (COMISSÃO EUROPEIA, 2020b), visando coordenar as restrições de viagens no bloco, que se revelou como uma proibição generalizada de viagens para a UE, aplicada pelos Estados-membros. Na sequência, a depender do quadro, baseandose em critérios epidemiológicos, podem ser apoiadas medidas paulatinas sucessivas de flexibilização dos controles, com abertura parcial de restrições. 
Em todo caso, para Carrera e Luk (2020), essa tolerância do sistema regional às restrições nacionais não pode ser encarada como carta-branca aos Estados-membros. O ônus da prova recai sobre os governos nacionais para justificar a adequação, necessidade e proporcionalidade das limitações jurídicas em relação à circulação de pessoas, sobretudo em face dos impactos nas liberdades comunitárias. As medidas devem ser adotadas nos limites do ordenamento comunitário, seguindo as recomendações internacionais, sob pena de esvaziar as instâncias supranacionais, devendo, ainda, atender a proporcionalidade e a não discriminação no direito europeu.

No caso da UE, as medidas restritivas das fases iniciais de contenção impactaram a livre circulação de pessoas ao reintroduzirem controles fronteiriços, que formaram uma ampla rede de restrições nacionais à mobilidade, sem coordenação significativa entre os Estados. Aliadas às proibições de viagens na UE, as restrições à circulação internacional de pessoas representaram uma proibição automática de entrada, sem avaliação individualizada dos motivos de entrada ou trânsito. Em consequência, observou-se uma prioridade geral dada à questão de segurança interna, em detrimento de considerações de saúde pública de indivíduos. As medidas priorizaram o papel dos guardas de fronteira na verificação das condições de entrada e circulação. Ao reduzirem a questão da saúde pública a uma perspectiva de ordem pública e segurança interna, as medidas materializaram uma recusa automática de entrada, afetando Estados-membros com base em critérios generalizados, o que contraria a obrigação de avaliação individualizada do sujeito em mobilidade no bojo de Schengen.

No que se refere ao MERCOSUL, as medidas de combate à COVID-19 adotadas pelos Estados Partes do bloco também afetaram significativamente o disciplinamento da mobilidade humana no espaço regional. Ainda que o arranjo mercosulino não tenha reconhecido um amplo direito de livre circulação de pessoas, com completa abolição de controles nas fronteiras internas ou pleno reconhecimento de um estatuto da cidadania regional, como já existe na UE, as ações adotadas pelos países apresentaram potencial para alterar o funcionamento do espaço regional. O modelo intergovernamental e os compromissos de incorporação e harmonização normativa, típicos do direito da integração, colocam a implementação da livre circulação de pessoas na dependência da atuação de cada Estado Parte, inexistindo maior supervisão comunitária. Esse sistema, em larga medida apoiado nas soberanias estatais, restou evidenciado na pandemia, com medidas nacionais de fechamento de fronteiras e proibições de entrada e circulação.

Como exemplos das medidas restritivas implementadas pelos Estados Partes originários do bloco, destacam-se: na Argentina, a proibição de entrada de estrangeiros não residentes, mediante o fechamento de fronteiras, inicialmente a partir do Decreto 274/2020 (ARGENTINA, 2020); no Brasil, 
a restrição de entrada de estrangeiros provenientes de países da América do Sul, cuja regulamentação foi prevista em portarias interministeriais, a exemplo da Portaria n. 8/2020 (BRASIL, 2020); no Paraguai, o fechamento dos pontos de controle migratório nas fronteiras, determinado, por exemplo, pelo Decreto n. 3458/2020 (PARAGUAI, 2020); e no Uruguai, o fechamento de fronteiras para estrangeiros e proibição de entradas e saídas para turismo (URUGUAI, 2020).

As iniciativas imediatas adotadas pelos governos da região revelam que as medidas restritivas à circulação internacional de pessoas apostaram no controle ou fechamento de fronteiras e na proibição de entradas como forma de conter a pandemia, reafirmando-se a soberania territorial. Tendo em vista que o sistema normativo mercosulino é pautado na intergovernabilidade, não prevendo espaço comum de livre mobilidade em acordo comunitário, é possível notar que as medidas seguiram os preceitos dos ordenamentos internos, em detrimento das normativas regionais. O bloco confere amplas prerrogativas de ação aos Estados, sobretudo diante da flexibilidade do direito da integração regional, revelando que, também no âmbito mercosulino, a ordem jurídica regional admitiu a atuação dos Estados Partes em matéria de limitação à circulação de pessoas, reafirmando a relevância normativa nacional que resulta em certo déficit de cooperação regional no enfrentamento da crise em matéria de mobilidade.

Em síntese, apesar de o MERCOSUL apresentar potencial para fornecer recursos normativos e institucionais, a crise do novo coronavírus escancarou a realidade jurídica da região, revelando que o bloco funcionou como mero sistema de justificação e informação mútua das medidas nacionais adotadas. Como exemplo, destaca-se a Declaração dos Presidentes do bloco sobre a coordenação regional para contenção e mitigação do coronavírus (MERCOSUL, 2020), que se refere a uma declaração conjunta de intenções, em que se reforça o compromisso de considerar as comunidades fronteiriças nas medidas de circulação, de notificar aos demais Estados sobre as restrições de fronteiras e de remover obstáculos contra a circulação de bens e serviços.

As iniciativas regionais reforçam a estrutura intergovernamental vigente, reafirmando a capacidade de atuação de cada Estado Parte em matéria de disciplinamento da livre circulação de pessoas no espaço regional, não avançando em uma maior integração jurídica. O interesse nacional ainda prevalece (RIGGIROZZI, 2020), o que se refletiu nos limites à liberdade de circulação no contexto de pandemia. Neste ponto, o questionamento que se levanta não é contra as medidas de restrição em si, mas contra a falta de maior coordenação regional, já que os blocos podem, na pandemia, favorecer maior convergência normativa, facilitar a mobilização de recursos, compartilhar informações e difundir boas práticas, ajustando medidas nacionais a preceitos regionais. 
A partir da análise, percebe-se que os dois blocos revelam uma dinâmica de disciplinamento da mobilidade humana que coloca a livre circulação como um valor do sistema regional, mas que não abre mão das atuações estatais, confirmando a hipótese proposta. No caso europeu, apesar das amarras do direito comunitário, os Estados-membros têm atuação tolerada pelas instâncias supranacionais, com desafio de preservar liberdades comunitárias. No MERCOSUL, a ordem regional autoriza maior intervenção dos Estados, com desafio de prosseguir em uma efetiva livre circulação.

\section{CONSIDERAÇÕES FINAIS}

A pandemia de COVID-19 trouxe transformações jurídicas que desafiaram a lógica da globalização e do regionalismo, a partir da reintrodução de barreiras às interações transfronteiriças, com efeitos especialmente sentidos em processos de integração. Apesar das incertezas da pandemia em referência, foi possível constatar que as limitações à liberdade de circulação de pessoas, nos processos de integração analisados, desafiaram a manutenção de espaços comuns de mobilidade, expondo a dinâmica de disciplinamento normativo da mobilidade humana em blocos regionais.

A partir das normativas comunitárias, analisadas no âmbito da UE, e das normativas regionais, vigentes no MERCOSUL, o artigo confirma a hipótese de que a liberdade de circulação de pessoas, apesar de ser um valor para a integração, tende a ser regulamentada de modo a conferir possibilidades de atuação aos Estados-membros, cujas competências de controle sobre o fluxo de pessoas vêm à tona em contextos de crise. As prerrogativas se materializam nos limites normativos nacionais impostos à circulação por razões de ordem pública, segurança interna, e, sobretudo, saúde pública, com restrições evidenciadas na pandemia de COVID-19, tanto na UE quanto no MERCOSUL, a partir do protagonismo conferido aos entes estatais.

No caso europeu, a reintrodução inicial de controles de fronteiras no espaço Schengen, aliada a proibições de viagem adotadas no espaço comum, evidenciaram a pressão sobre o sistema comunitário para a retomada da atuação estatal no controle da mobilidade humana no bloco, não obstante as amarras do direito da UE. As instâncias supranacionais buscaram contrabalançar as medidas restritivas, porém as normativas analisadas revelaram uma ênfase no controle de fronteiras, como uma defesa da ordem pública e da segurança, acirrando controles sobre a mobilidade de forma generalizada, o que poderia esvaziar instâncias comunitárias e arriscar a liberdade de circulação.

No caso do MERCOSUL, as respostas à disseminação da COVID-19 reafirmaram a ênfase estatal no controle da mobilidade humana no bloco. Graças à estrutura intergovernamental e aos preceitos do direito da integração regional, as medidas restritivas se pautaram na atuação de cada 
Estado Parte, com foco no fechamento de fronteiras e na restrição de entrada e de circulação de pessoas. Apesar da evolução do bloco, o sistema jurídico do MERCOSUL ainda está apegado à soberania territorial, o que se tornou notório na pandemia. O arranjo mercosulino funcionou como um sistema de justificação normativa e de notificação mútua das medidas de contenção, faltando maior coordenação regional em termos de mobilidade, o que gerou uma introversão normativa estatal que pode adiar a plena efetivação da política de livre circulação.

Em linhas gerais, a crise de saúde pública condicionou uma situação normativa paradoxal nos processos analisados. Por um lado, o receio de que a manutenção da plena circulação de pessoas agravasse a disseminação do novo coronavírus, atraindo a atuação dos Estados-membros diante de ameaças à ordem e à saúde pública. Por outro lado, as restrições foram confrontadas com as garantias do sistema regional, em face da cidadania e das liberdades do mercado comum, que podem facilitar o trânsito de profissionais, prestadores de serviços e de bens necessários ao suprimento das cadeias de produção, de modo que uma discussão unicamente nacional do problema põe em risco a integração no contexto de transformação da globalização e do regionalismo.

Portanto, o foco exclusivo nas respostas nacionais esvazia instâncias regionais em detrimento de um tratamento conjunto e atento às recomendações internacionais e aos ordenamentos regionais, em um esforço integrado de superação dos desafios apresentados. Afinal, assim como a mobilidade humana enseja uma conformação entre os níveis de disciplinamento nacional, regional e global, também suas restrições são instadas a equilibrar as competências nacionais de controle com as competências regionais e com as recomendações internacionais das instâncias especializadas no tema.

\section{REFERÊNCIAS}

ACOSTA, Diego. Global Migration Law and Regional Free Movement: Compliance and Adjudication - The Case of South America. American Journal of International Law, AJIL Unbound, [s. l.], v. 111, p. 159-164, 2017. Disponível em: https://bit.ly/3d81YJe. Acesso em: 13 abr. 2020.

ARGENTINA. Decreto 274/2020, 16 de marzo de 2020. Prohibición de ingresso al territorio nacional. Boletín Oficial de la República Argentina, Buenos Aires, 16 de marzo de 2020. Disponível em: https://bit.ly/2LAt3bS. Acesso em: 22 abr. 2020.

BALASSA, Bela. Teoria da integração econômica. Lisboa: Livraria Clássica, 1961.

BARBULESCU, Roxana. From international migration to freedom of movement and back? Southern Europeans moving north in the era of retrenchment of freedom of movement rights. In: 
LAFLEUR, Jean; STANEK, Mikolaj (ed.). South-North Migration of EU Citizens in Times of Crisis. Basel: Springer, 2017. p. 15-31.

BITTENCOURT, Renato. Pandemia, isolamento social e colapso global. Revista Espaço Acadêmico, Maringá, v. 19, n. 222, p. 168-178, 2020. Disponível em: https://bit.ly/2Z6p6nb. Acesso em: 11 maio 2020.

BOHLKE, Marcelo. O processo de integração regional e a autonomia do seu ordenamento jurídico. Curitiba: Juruá, 2002.

BRASIL. Portaria n. 8, de 02 de abril de 2020. Dispõe sobre a restrição excepcional e temporária de entrada no País de estrangeiros provenientes dos países que relaciona. Diário Oficial da União, Brasília, DF, 02 de abril de 2020. Disponível em: https://bit.ly/366435o. Acesso em: 16 abr. 2020.

BRUMAT, Leiza; ACOSTA, Diego. Three generations of free movement of regional migrants in Mercosur: Any influence from the EU? In: GEDDES, Andrew et al. (ed.). The dynamics of regional migration governance. Cheltenham: Elgar Publishing, 2019. p. 54-72.

BRUYCKER, Philippe. The European Union: from freedom of movement in the internal market to the abolition of internal borders in the area of freedom, security and justice. In: NITA, Sonia et al. (org.). Migration, Free Movement and Regional Integration. Paris: UNESCO, 2018. p. 287-311.

CARRERA, Sergio; LUK, Ngo Chun. Love thy neighbour? Coronavirus politics and their impact on EU freedoms and rule of law in the Schengen Area. Bruxelas: CEPS, 2020. Disponível em: https://bit.ly/2WYPHQp. Acesso em: 8 maio 2020.

CHINAZZI, Matteo et al. The effect of travel restrictions on the spread of the 2019 novel coronavirus (COVID-19) outbreak. Science, [s. l.], v. 368, p. 395-400, 2020. Disponível em: https://bit.ly/2Tc0w0k. Acesso em: 8 maio 2020.

COMISSÃO EUROPEIA. COVID-19: Temporary Restriction on Non-Essential Travel to the EU. 16 March 2020b. Disponível em: https://bit.ly/363GzxQ. Acesso em: 8 maio 2020.

COMISSÃO EUROPEIA. Guidelines for border management measures to protect health and ensure the availability of goods and essential services. 16 March 2020a. Disponível em: https://bit.ly/3cGZPE6. Acesso em: 8 maio 2020.

COSTA, Vitória Volcato da; VIEIRA, Luciane Klein. Nacionalismo, xenofobia e União Europeia: barreiras à livre circulação de pessoas e ameaças ao futuro do bloco europeu. Revista da Faculdade de Direito UFPR, Curitiba, v. 64, n. 3, p. 133-160, 2019. Disponível em: https://bit.ly/3dI8OVA. Acesso em: 11 mar. 2020.

DEL'OLMO, Florisbal; ROTTA, Guilherme. “BREXIT”: da integração regional à política de controle de mobilidade humana. Revista Brasileira de Direito Internacional, Curitiba, v. 2, n. 2, p. 100-117, jul./dez. 2016. Disponível em: https://bit.ly/2Lx6V23. Acesso em: 22 abr. 2020.

DIZ, Jamile Bergamaschine Mata; JAEGER JÚNIOR, Augusto. Por uma teoria jurídica da integração regional: a inter-relação direito interno, direito internacional público e direito da 
integração. Revista de Direito Internacional, Brasília, v. 12, n. 2, p. 138-158, 2015. Disponível em: https://bit.ly/2T9Vy41. Acesso em: 6 maio 2020.

DOLINGER, Jacob; TIBURCIO, Carmen. Direito Internacional Privado. Rio de Janeiro: Forense, 2018.

EUR-LEX. Acto Único Europeu. 29 junho 1987. Disponível em: https://bit.ly/2ZAIau3. Acesso em: 13 mar. 2020.

EUR-LEX. Código das Fronteiras Schengen. 9 março 2016. Disponível em: https://bit.ly/3bCMz1Q. Acesso em: 13 mar. 2020.

EUR-LEX. Directiva 2004/38/CE do Parlamento Europeu e do Conselho. 29 abril 2004. Disponível em: https://bit.ly/2yaIVi4. Acesso em: 13 mar. 2020.

FEFERBAUM, Marina. Comunidades econômicas na proteção aos direitos humanos: desafios e perspectivas de uma agenda de direitos humanos na integração regional. Revista da Faculdade de Direito UFPR, Curitiba, v. 62, n. 1, p. 155-182, 2017. Disponível em: https://bit.ly/2ySh6vq. Acesso em: 10 maio 2020.

FLEW, Terry. Populism and Globalization: Towards a Post-Global Era? Presentation to School of Media and Public Affairs seminar series. George Washington University, Washington DC, 2019. Disponível em: https://bit.ly/2LAlodv. Acesso em: 27 abr. 2020.

GIDDENS, Anthony. O mundo na era da globalização. Lisboa: Presença, 2006.

GÜLZAU, Fabian; MAU, Steffen; ZAUN, Natascha. Regional Mobility Spaces? Visa Waiver Policies and Regional Integration. International Migration, [s. l.], v. 54, n. 6, p. 164-180, 2016. Disponível em: https://bit.ly/2Z82tP7. Acesso em: 16 mar. 2020.

HEES, Carlos Alexandre; VENY, Leticia; HEES, Luciane Weber Baia. Direito internacional da mobilidade humana: o caso dos haitianos nos Estados Unidos. Acta Científica, São Paulo, v. 26, n. 2, p. 41-55, 2018. Disponível em: https://bit.ly/3fT2mg9. Acesso em: 30 mar. 2020.

HERZ, Mônica; HOFFMANN, Andrea. Organizações internacionais: história e práticas. Rio de Janeiro: Elsevier, 2004.

KRAEMER, Moritz U. G. et al. The effect of human mobility and control measures on the COVID19 epidemic in China. Science, [s. l.], v. 368, p. 493-497, 2020. Disponível em:

https://bit.ly/3bDZY9G. Acesso em: 10 maio 2020.

LECHNER, Frank; BOLI, John. General Introduction. In: LECHNER, Frank; BOLI, John. (ed.). The globalization reader. Nova Jersey: Wiley Blackwell, 2019.

MENDES, José Sacchetta Ramos. ¿Puertas abiertas? Migrações regionais, direito e integração na Comunidade Andina de Nações e no Mercosul. Caderno CRH, Salvador, v. 29, n. 3, p. 77-91, 2016. Disponível em: https://bit.ly/2zIcN5T. Acesso em: 20 abr. 2020. 
MERCOSUL. Acordo sobre Residência para Nacionais dos Estados Partes do MERCOSUL. 6 dezembro 2002. Disponível em: https://bit.ly/3cDiIHN. Acesso em: 16 abr. 2020.

MERCOSUL. Declaracion de los presidentes del MERCOSUR sobre cordinacion regional para la contencion y mitigacion del coronavirus y su impacto. 18 marzo 2020. Disponível em: https://bit.ly/3cFf546. Acesso em: 16 abr. 2020.

MERCOSUL. Estatuto da Cidadania do MERCOSUL. Plano de Ação. 16 dezembro 2010. Disponível em: https://bit.ly/2Z43vvA. Acesso em: 16 abr. 2020.

MESQUITA, Rafael. Regionalismo, Integração regional e as relações internacionais: uma introdução teórica. Revista de Estudos Internacionais, João Pessoa, v. 10, n. 1, p. 3-22, 2019. Disponível em: https://bit.ly/368qEyj. Acesso em: 10 maio 2020.

MOURA, Aline Beltrame de. A criação de um espaço de livre residência no Mercosul sob a perspectiva teleológica da integração regional: aspectos normativos e sociais dos acordos de residência. Revista de Direito Internacional, Brasília, v. 12, n. 2, p. 630-648, 2015. Disponível em: https://bit.ly/2y7TUJ9. Acesso em: 19 abr. 2020.

MUCELIN, Guilherme; D’AQUINO, Lúcia Souza. O papel do direito do consumidor para o bemestar da população brasileira e o enfrentamento à pandemia de COVID-19. Revista de Direito do Consumidor, [s. l.], v. 129, p. 17-46, 2020. Disponível em: https://bit.ly/3fTmHSH. Acesso em: 2 maio 2020.

OLIVEIRA NETO, Thiago; GARCIA, Tatiana de Souza Leite; SPINUSSI, Eduardo. Pandemia de COVID-19, as fronteiras pelo mundo e o transporte aéreo na Itália. Confins, [s. l.], n. 44, p. 1-14, 2020. Disponível em: https://bit.ly/3cF1oCe. Acesso em: 24 abr. 2020.

ORGANIZAÇÃO MUNDIAL DA SAÚDE (OMS). Updated WHO recommendations for international traffic in relation to COVID-19 outbreak. COVID-19 Travel Advice, 29 February 2020. Disponível em: https://bit.ly/2X1jF6n. Acesso em: 14 abr. 2020.

PARAGUAI. Decreto N 3458/2020, de 17 de marzo de 2020. Por el cual se dispone el cierre parcial y temporal de puestos de control migratorio en frontera, como medida ante el riesgo de expansion del corona virus (COVID-19). Gaceta Oficial de la República del Paraguay, Assunção, 17 de março de 2020. Disponível em: https://bit.ly/2Lx9Ebt. Acesso em: 18 abr. 2020.

PARLAMENTO EUROPEU. Livre circulação de pessoas. Ficha técnica da UE. 2020. Disponível em: https://bit.ly/2WCF4n6. Acesso em: 10 maio 2020.

RIGGIROZZI, Pía. Coronavirus y el desafío para la gobernanza regional en América Latina. Análisis Carolina, Madri, n. 12, p. 1-13, 2020. Disponível em: https://bit.ly/3bw2JtS. Acesso em: 10 maio 2020.

SALAZAR, Noel B. Mobility. Revista Interdisciplinar de Mobilidade Humana, Brasília, v. 27, n. 57, p. 13-24, 2019. Disponível em: https://bit.ly/3bCJOh9. Acesso em: 30 mar. 2020.

SALZMANN, Antonio. El contenido jurídico de la libre circulación de personas en el Mercosur: balance y perspectivas. In: GOIZUETA VÉRTIZ, Juana et al. (ed.). La libre circulación de 
personas en los sistemas de integración económica: modelos comparados: Unión Europea, Mercosur y Comunidad Andina. Navarra: Thomson Reuters Aranzadi, 2012. p. 163-185.

SZYMAŃSKA, Jolanta. The Schengen Area and the Coronavirus Pandemic. The Polish Institute of International Affairs, Varsóvia, v. 1.492, n. 62, 2020. Disponível em: https://bit.ly/3dV9S8L. Acesso em: 30 abr. 2020.

UNIÃO EUROPEIA. Temporary Reintroduction of Border Control. European Comission, 2020. Disponível em: https://bit.ly/2WAboXT. Acesso em: 11 maio 2020.

URUGUAI. Ministerio de Defensa Nacional. Protocolo de actuación para los Pasos de Frontera respecto al Covid-19. Montevidéu, 26 de marzo de 2020. Disponível em: https://bit.ly/364EL7S. Acesso em: 18 abr. 2020.

VENERAL, Débora Cristina; KNIHS, Karla Kariny. Globalização, soberania e os atuais contornos da integração regional no âmbito do Mercosul. Caderno da Escola Superior de Gestão Pública, Política, Jurídica e Segurança, Curitiba, v. 1, n. 1, p. 263-289, 2018. Disponível em: https://bit.ly/2LAvjQh. Acesso em: 14 mar. 2020.

VENTURA, Deisy. Mobilidade humana e saúde global. Revista USP, São Paulo, n. 107, p. 55-64, 2015. Disponível em: https://bit.ly/2WzuDRt. Acesso em: 16 abr. 2020.

VIEIRA, Luciane Klein; COSTA; Vitória Volcato da. A livre circulação de pessoas no Mercosul e na União Europeia: perspectivas e desafios para o futuro. Revista Brasileira de Direito

Internacional, Porto Alegre, v. 4, n. 2, p. 1-21, jul./dez. 2018. Disponível em: https://bit.ly/2TbFAGO. Acesso em: 16 abr. 2020.

VILLAMAR, María del Carmen Villarreal; ALMEIDA, Gisele Maria Ribeiro de. Mobilidade humana: perspectivas e desafios. Terceiro Milênio, Campos dos Goytacazes, v. 8, n. 1, p. 7-18, 2017. Disponível em: https://bit.ly/2X2bAhK. Acesso em: 2 maio 2020.

WERMUTH, Maiquel Ângelo Dezordi; MORAIS, José Luis Bolzan de. Da exceção agambeniana à constituição planetária de Ferrajoli: desafios impostos pela pandemia do novo coronavírus às categorias jurídico-políticas tradicionais. Revista Eletrônica do Curso de Direito da UFSM, Santa Maria, v. 15, n. 1, p. 1-29, 2020. Disponível em: https://bit.ly/3cEcjvV. Acesso em: 29 abr. 2020.

João Mauricio Malta Cavalcante Filho Doutorando em Direito Internacional FLattes iD: http://lattes.cnpq.br/5433796577283975

E-mail: joao.malta@ufpe.br

Eugênia Cristina Nilsen Ribeiro Barza

Doutora em Direito

9Lattes iD: http://lattes.cnpq.br/2199007432751774

E-mail: eugenia.barza@ufpe.br 